\title{
Duas entrevistas com Paul Mattick
}

A Paul Mattick Interview (J. J. Lebel). 1975. Versão de referência. Disponível em: http://libcom.org/library/mattick-interview-by-jilebel Acesso em: 8 jan 2015.

Lotta Continua Interview with Paul Mattick. 1977. Versão de referência. Disponível em: http://libcom.org/library/lotta-continua-interview-with-paul-mattick Acesso em: 8 jan 2015.

\section{TRADUÇÃO:}

Luciane Manika Espíndola Graduanda em Ciências Sociais pela UFSC

luhmanika@gmail.com

Originais recebidos em: 21/01/2015

Aceito para publicação em: 24/01/2015

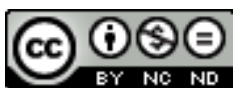

Atribuição-Uso Não-Comercial-Vedada a criação de obras derivadas 3.0 Unported License. 


\section{Nota da tradutora}

O presente trabalho se constitui na tradução de duas entrevistas realizadas com o eletricista, mecânico, editor, escritor e pensador revolucionário proletário Paul Mattick. Autor de obras cardinais como "Marx e Keynes: os limites da economia mista" (1969) em que, na contramão do pensamento dos economistas de esquerda de sua época, afirma a incompatibilidade das teorias dos dois autores, e "Marxismo: último refúgio da burguesia?", obra póstuma organizada e publicada por seu filho Paul Mattick Júnior em 1983, onde são apresentadas análises sobre a sociedade capitalista e sua oposição revolucionária, a história do movimento socialista, as tentativas de superação do capitalismo e os desdobramentos dessas experiências históricas.

A primeira entrevista traduzida foi concedida a Jean-Jacques Lebel ${ }^{1}$ em fevereiro de 1975, na qual Mattick discute as concepções de Anton Pannekoek, a formação e composição dos conselhos proletários, analisando também experiências históricas de movimentos revolucionários autônomos. Realizada para um programa de rádio com a temática do sistema de conselhos proletários, a entrevista nunca foi ao ar. Mais tarde, a versão original em inglês e uma versão traduzida para o francês foram incluídas como apêndice de edições nesses idiomas da obra "Conselhos Operários" de Pannekoek.

A segunda entrevista foi realizada em outubro de 1977 pelo grupo radical italiano Lotta Continua ${ }^{2}$, e nela Mattick aborda assuntos como crise, organização e revolução. Esta tradução foi realizada a partir de uma versão em inglês da entrevista publicada originalmente no n. 5 do jornal estadunidense Root \& Branch em 1978.

Paul Mattick é considerado, ao lado de Anton Pannekoek e Karl Korsch, um dos principais autores da corrente comunista conselhista - polo aglutinador de militantes pensadores antibolcheviques - que entende que a substituição do capitalismo só pode ser realizada pela ação dos próprios interessados na sua abolição, os trabalhadores explorados, por meio de formas de organização e de instituições autônomas tais como o sistema de conselhos proletários.

\footnotetext{
${ }^{1}$ Escritor e artista plástico francês. Em 1968 se organizou politicamente nos grupos Noir et Rouge (Negro e Vermelho) e Informations et Correspondences Ouvrières (Informações e Correspondências Operárias).

${ }^{2}$ Lotta Continua (Luta Contínua), fundada em 1969 e dissolvida em 1976, foi uma das principais organizações da esquerda extraparlamentar italiana, de orientação comunista revolucionária, entre o final dos anos 1960 e a primeira metade dos anos 1970.
}

Em Debat: Rev. Dig., ISSNe 1980-3532, Florianópolis, n. 10, p. 141-160, jul-dez, 2013. 
Oriundo de família proletária com trajetória socialista, Mattick nasceu em 1904 na Pomerânia alemã, atual Polônia. Sua trajetória ímpar começa na adolescência quando participava de movimentos reivindicatórios e de ação direta no interior das fábricas onde trabalhou como operário eletricista e mecânico da companhia Siemens de Berlim, ao final da primeira guerra mundial. Em 1920 ainda na Alemanha, participou da fundação do Partido Comunista Operário da Alemanha (KAPD) de tendência antiparlamentar em contraposição ao Partido Comunista Alemão (KPD) que sustentava posições parlamentaristas.

Em 1926, perante difíceis condições de sobrevivência - que incluíam desemprego e perseguições policial e nazista - Mattick decide emigrar para os EUA com alguns camaradas. Na cidade de Chicago trabalha para a Western Electric e se vincula à organização sindical internacionalista e anticapitalista Industrial Workers of the World IWW (Trabalhadores Industriais do Mundo) nela permanecendo nos anos seguintes.

Desempregado diante da 1929 Mattick atua em movimentos reivindicatórios de ação direta, e passa a coordenar grupos de discussão entre operários desempregados de Chicago sobre "O Capital” de Marx. Em 1934, organizado com um grupo de comunistas de conselhos nos EUA e em contato com camaradas alemães e holandeses, edita as revistas International Council Correspondence (Correspondência Conselhista Internacional) em 1938 renomeada para Living Marxism (Marxismo Vivo) e em 1942 para New Essays (Novos Ensaios).

Durante a II Guerra Mundial Mattick volta a trabalhar como metalúrgico e se confronta politicamente com as burocracias sindicais contrárias à organização autônoma dos trabalhadores. Em 1948 transfere-se para Nova Iorque onde, em função de dificuldades materiais, com a entrada dos EUA na guerra e a ofensiva macarthista sobre a esquerda, se retira no início dos anos 50 com a esposa Ilse e o filho Paul Mattick Júnior para uma pequena propriedade rural em Vermont, sobrevivendo como escritor e da realização de trabalhos ocasionais.

Nos anos 60 a família se muda para Boston em virtude de um trabalho de Ilse em Cambridge. Nos anos seguintes, Mattick consegue se dedicar aos estudos e à escrita, publicando artigos novos e antigos em diversas línguas, participando de palestras acadêmicas que atraíram grande atenção do público jovem, além de uma oportunidade de 
trabalho temporário como professor visitante na Universidade de Roskilde na Dinamarca entre 1974 e 1975.

Paul Mattick morreu em fevereiro de 1981 deixando uma produção que ultrapassa 500 trabalhos publicados. Sua contribuição para o desenvolvimento do marxismo entendido como expressão da luta revolucionária do proletariado pelo comunismo - pode ser rigorosamente avaliada ao se considerar três características cuja ausência na trajetória de Mattick convergem para situá-lo em uma posição peculiar quando comparado a outros pensadores marxistas do chamado "marxismo ocidental" (Lukács, Gramsci, Adorno, Walter Benjamin, Sartre, dentre outros): desvinculação pessoal com o proletariado, relação profissional com a academia e interesse pelos aspectos filosóficos do marxismo, em detrimento dos aspectos políticos e, sobretudo, econômicos. Assim, se pode encontrar uma pista dos motivos acerca do pouco conhecimento sobre seu pensamento e sua prática. E para os mais apressados que tentam situar sua contribuição na esfera de um marxismo economicista, basta lembrar que certa feita, referindo-se à popularidade das touradas no Estado Espanhol, comentou que "seria impossível construir o socialismo em um país no qual seus habitantes se divertem contemplando a tortura de um animal." (JATG, 2002, p. 311).

\section{Referências bibliográficas}

ARQUIVO KURASJE. Mattick, Paul (1904-1981). Disponível em: http://marxists.org/glossary/people/m/a.htm\#mattick-paul. Acesso em: 09 jan 2015.

JATG. Paul Mattick (1904-1981). In: GUERRERO, Diego (coord.) Lecturas de economía política. Madrid: Síntesis, 2002. p. 301-311.

REEVE, Charles. Paul Mattick (1904-1981). In: MATTICK, Paul. De la Pauvreté et de la Nature Fetichiste de l'Economie. Paris : Ed. Ab Irato, 1998. 


\section{Entrevista de Paul Mattick a J. J. Lebel (1975)}

J. J. Lebel (JJL): Que relevância tem o livro de Pannekoek na Europa de hoje? ${ }^{3}$ Você pensa que a memória analítica e a teoria das experiências passadas do comunismo de conselhos, como Pannekoek as expressou, podem ser "ouvidas" e entendidas pelo proletariado aqui e agora?

Paul Mattick (PM): Um livro como o de Pannekoek não tem necessidade de relevância imediata. Preocupa-se com um período histórico: com acontecimentos passados, bem como com possíveis experiências futuras, em que o fenômeno do aparecimento e desaparecimento dos conselhos proletários indica uma tendência de desenvolvimento da luta de classe do proletariado e seus objetivos de mudança. Como qualquer outra coisa, as formas de luta de classes são históricas no sentido de que elas surgem muito antes de sua plena realização se tornar uma possibilidade real. Em uma forma embrionária, por exemplo, os sindicatos surgiram espontaneamente como instrumentos de resistência proletária contra a exploração nos primórdios do desenvolvimento do capitalismo, para desaparecer novamente apenas por causa de obstáculos objetivamente determinados pelo seu desenvolvimento ulterior. No entanto, sua irrelevância temporária não impediu o seu pleno desdobramento sob condições alteradas, o que determinou seu caráter, possibilidades e limitações. Da mesma forma, os conselhos proletários apareceram sob condições históricas que impediam a plena realização de todas as suas potencialidades revolucionárias. O conteúdo social das revoluções em que os primeiros conselhos proletários surgiram não era adequado à sua forma de organização. Os conselhos proletários na Rússia de 1905 e 1917, por exemplo, lutaram por uma democracia burguesa constitucional e por objetivos sindicais como jornada de oito horas e maior remuneração. Os conselhos proletários na Alemanha de 1918 renunciaram ao seu poder político momentaneamente conquistado em favor da Assembleia Nacional burguesa e de um ilusório caminho evolutivo da social-democracia alemã. Em ambos os casos, os conselhos proletários somente poderiam se auto extinguir quando sua forma de organização entrasse em contradição com seus limitados objetivos políticos e sociais.

\footnotetext{
3 Refere-se à obra “Conselhos Operários” publicada originalmente em 1946. (Nota da tradutora)
} 
Enquanto na Rússia foi a imaturidade das condições objetivas para uma revolução socialista, na Alemanha foi a indisposição subjetiva de realizar o socialismo por meios revolucionários que representaram o declínio e, por fim, a destruição forçada do movimento dos conselhos. No entanto, foram os conselhos proletários - e não as organizações trabalhistas tradicionais - que garantiram o sucesso dos levantes revolucionários apesar das limitações que demonstraram. Embora os conselhos proletários tenham revelado que o proletariado é plenamente capaz de desenvolver instituições revolucionárias próprias - seja em combinação com as organizações trabalhistas tradicionais, ou em oposição a elas - no momento de sua formação o proletariado possuía somente vagos conceitos, ou nenhum, de como consolidar seu poder e usá-lo para transformar a sociedade. Deste modo, se valeram das instituições políticas do passado. A questão de haver ou não a ideia conselhista - como elaborada por Pannekoek - poder ser compreendida e retomada pelo proletariado hoje, é um tanto estranha, porque a ideia dos conselhos não implica nem mais nem menos do que a autoorganização do proletariado, onde e quando isso se torna um imperativo inevitável na luta por suas necessidades imediatas ou para objetivos distantes, que podem ser alcançados ou não, ou que estão em oposição de fato às organizações trabalhistas tradicionais, como sindicatos e partidos políticos. Uma luta específica no interior de uma fábrica ou indústria para se estabelecer plenamente pode exigir para sua extensão à áreas maiores e mais numerosas, um sistema de delegados, comitês de ação, ou conselhos proletários. Tais lutas podem ter apoio ou não das organizações trabalhistas existentes. Se não, elas terão que ser conduzidas de modo independente pelos próprios proletários combativos, o que implica na sua auto-organização. Em circunstâncias revolucionárias, isto pode muito bem levar a uma grande propagação do sistema de conselhos proletários, como base de uma total reorganização da estrutura social. É claro que, sem uma situação de revolução, expressando uma condição de crise social, o proletariado não vai se preocupar com as implicações mais amplas do sistema de conselhos, mesmo que possa se organizar para determinadas lutas por meio de conselhos. A descrição de Pannekoek da teoria e prática dos conselhos proletários se refere assim apenas às próprias experiências dos trabalhadores. Mas o que é experimentado também pode ser compreendido e, em condições favoráveis, ser aplicado na sua luta no interior e contra o sistema capitalista.

Em Debat: Rev. Dig., ISSNe 1980-3532, Florianópolis, n. 10, p. 141-160, jul-dez, 2013. 
JJL: Como você analisa o surgimento do livro de Pannekoek em relação com a prática dele (na Alemanha ou Holanda)? Você considera que o livro e o ensaio dele sobre sindicalismo (na revista Living Marxism) se aplicam às condições atuais?

PM: Pannekoek escreveu seu livro sobre os conselhos proletários durante a Segunda Guerra Mundial. Foi um resumo de sua experiência de vida, da teoria e prática do movimento operário internacional e do desenvolvimento e transformação do capitalismo em várias nações e em geral. Ele conclui com o triunfo temporário de um revivido embora modificado - capitalismo, e com a total sujeição dos interesses proletários às necessidades competitivas de sistemas capitalistas rivais em preparação para novos conflitos imperialistas. Ao contrário das classes dominantes, que se adaptam rapidamente às novas condições, a classe proletária, por ainda aderir a ideias e atividades tradicionais, se encontra em uma situação de impotência e aparente desesperança. E como as mudanças socioeconômicas alteram as ideias apenas gradualmente, leva um tempo considerável antes de surgirem novos movimentos do mundo do trabalho adaptados às novas condições. Embora a existência ininterrupta do capitalismo - sob as formas privada ou capitalista de Estado - demonstra que a expectativa de crescimento de um novo movimento operário, na esteira da Segunda Guerra Mundial, foi prematura, a contínua resiliência do capitalismo não afasta suas contradições imanentes e, portanto, não vai liberar o proletariado da necessidade de colocar um fim a tal sistema. Claro que, com o capitalismo ainda em vigor, as velhas organizações trabalhistas (partidos parlamentares e sindicatos) poderiam ser mantidas. Mas elas já são reconhecidas, e se reconhecem a si mesmas, como parte integrante do capitalismo, destinado a ir abaixo com o sistema do qual sua existência depende. Muito antes de se tornar um fato óbvio, estava claro para Pannekoek que o antigo movimento operário era um produto histórico do capitalismo nascente, vinculado a este estágio particular de desenvolvimento, em que a questão da revolução e do socialismo apenas poderia ser levantada, mas não respondida. Em tal momento, essas organizações trabalhistas estavam destinadas a se degenerarem em ferramentas do capitalismo. O socialismo dependia agora da ascensão de um novo movimento operário, capaz de criar as condições prévias para o autogoverno proletário. 
Se o proletariado for assumir o processo de produção e determinar a distribuição de seus produtos, ele precisa, mesmo antes desta transformação revolucionária, atuar e se organizar de modo completamente diferente do passado. Em ambas as formas de organização, partidos parlamentares e sindicatos, o proletariado delega seu poder para grupos particulares de líderes e gestores, que supostamente agem em seu nome, mas na verdade apenas promovem seus próprios e distintos interesses. $\mathrm{O}$ proletariado perdeu o controle sobre suas próprias organizações. Mas mesmo que não tivesse sido assim, essas organizações eram totalmente impróprias para servir como instrumentos para a revolução proletária ou para a construção do socialismo. Partidos parlamentares foram um produto da sociedade burguesa, uma expressão da democracia política do capitalismo laissez-faire e apenas dentro desse contexto faz sentido. Eles não têm lugar no socialismo, sociedade que se supõe acabar com conflitos de ordem política, dado que acaba com interesses especiais e relações sociais de classe. Como não há lugar nem necessidade de partidos políticos em uma sociedade socialista, sua superfluidade futura já explica sua ineficácia como instrumento de mudança revolucionária. Sindicatos também não têm funções no socialismo, sociedade que desconhece relações salariais e nem organiza a produção de acordo com ramos profissionais e industriais específicos, mas sim de acordo com as necessidades sociais. Como a emancipação da classe proletária somente pode ser realizada pelos próprios proletários, eles têm que se organizar enquanto classe para tomar e manter o poder. Entretanto, nas condições atuais, que não são de natureza revolucionária, a forma conselhista das atividades proletárias não evidencia diretamente suas potencialidades revolucionárias mais amplas, mas é mera expressão da realização da integração das organizações trabalhistas tradicionais no sistema capitalista. Partidos parlamentares e sindicatos perdem sua limitada eficácia quando deixa de ser possível combinar melhoria dos padrões de vida do proletariado com progressiva expansão de capital. Sob condições que impedem uma acumulação capitalista suficiente, ou seja, em condições de crise econômica, as atividades reformistas de partidos políticos e sindicatos perdem eficácia e essas organizações se abstêm de suas supostas funções, uma vez que jamais colocariam em risco o próprio sistema capitalista. Elas preferirão tentar ajudar a sustentar o sistema, a ponto de sabotar diretamente as aspirações proletárias por melhores condições de vida e trabalho. Ajudarão o capitalismo a superar sua crise à custa do 
proletariado. Em tal situação, os proletários, não dispostos a se submeterem aos ditames do capital, são obrigados a recorrer a atividades não sancionadas pelas organizações trabalhistas oficiais, as chamadas greves selvagens, ocupações de fábricas e outras formas de ação direta, fora do controle das organizações trabalhistas institucionalizadas. Estas atividades de autodeterminação, com a sua temporária estrutura conselhista, indicam a possibilidade de sua aplicação radical em situações de ascenso revolucionário, substituindo as formas tradicionais de organização, que se tornaram obstáculos tanto na luta pelas necessidades imediatas quanto para objetivos revolucionários.

JJL: Você pode dar alguns exemplos práticos e concretos de como os conselhos proletários funcionam (na Rússia, Alemanha, Hungria, etc.), e como eles diferem dos partidos tradicionais e das organizações sindicais? Quais são as diferenças básicas? Como partido e conselho ou sindicato se confrontam?

PM: Toda greve, manifestação, ocupação ou outros tipos de atividade anticapitalista que ignora as organizações trabalhistas oficiais e escapa de seus controles, assume o caráter de ação independente da classe proletária, que determina sua própria organização e procedimentos, pode ser considerada como um movimento conselhista. Em uma escala maior, a organização espontânea de levantes revolucionários, como a que ocorreu na Rússia em 1905 e 1917, na Alemanha, em 1918, e mais tarde - contra as autoridades do Capitalismo de Estado - na Hungria, Tchecoslováquia e Polônia, se valeram dos conselhos proletários como única forma possível de ações de classe proletária em uma condição na qual todas as instituições e organizações estabelecidas se tornaram defensoras do status quo. Esses conselhos surgem por necessidade, mas também por causa da oportunidade proporcionada pelos processos de produção capitalista, que já são as formas "naturais" de atividades e organização de classe dos proletários. Aqui, o proletariado está "organizado" como classe contra a classe capitalista. O local de exploração também é o veículo para a sua resistência à opressão capitalista. "Organizado" pelos seus governantes em fábricas, indústrias, exércitos, ou em bairros proletários afastados, o proletariado tornou essas "organizações" como suas próprias, valendo-se delas para seus esforços independentes e sob sua própria liderança. Tais líderes foram 
eleitos de seu meio e revogáveis a qualquer tempo. Desse modo, a divergência historicamente desenvolvida entre as organizações trabalhistas institucionalizadas e o proletariado em geral foi eliminada e a aparente contradição entre organização e espontaneidade, resolvida. Até agora, com certeza, os conselhos proletários encontraram suas limitações nos marcos de ações espontâneas em condições desfavoráveis. Eles têm sido a expressão esporádica de movimentos esporádicos, ainda incapazes de transformar seu potencial para tornar realidade a estrutura organizacional das relações de não exploração. A diferença básica entre o movimento dos conselhos e as organizações trabalhistas tradicionais é que, enquanto estas perdem suas funções em um capitalismo decadente e nada tem a contribuir para a construção do socialismo, aquele não apenas se torna a única forma de ações efetivas do proletariado - independentemente do estado em que o capitalismo se encontra - mas é, ao mesmo tempo, a prefiguração da estrutura organizacional da sociedade socialista.

JJL: Você enxerga alguma semelhança (na intenção, resultado ou forma) entre o comunismo de conselhos e as atuais lutas proletárias nos EUA e Europa? algum dos eventos recentes indicam uma evolução significativa e qualitativa para um tipo diferente de sociedade? Ou, você pensa que as recentes lutas destacadas (Maio de 68, Lordstown, LIP, etc) são apenas mais das mesmas velhas modernizações programadas do capitalismo?

PM: Há, sem dúvida, uma conexão entre as manifestações recentes de ações autodeterminadas do proletariado, como o movimento de Maio de 1968 na França, a ocupação da LIP, mas também as rebeliões dos trabalhadores na Alemanha Oriental, Polônia e mesmo Rússia, e o "instintivo" e consciente reconhecimento de que as formas de ação representadas pela concepção e realidade dos conselhos proletários são o requisito necessário de lutas proletárias nas condições vigentes. Mesmo greves não oficiais nos EUA podem ser consideradas como uma primeira expressão do desenvolvimento de uma consciência de classe, dirigidas não somente contra o óbvio inimigo capitalista, mas também contra o movimento trabalhista oficial integrado pelo capitalismo. No entanto, as tradições ainda são poderosas e as instituições alimentadas 
por elas constituem parte da capacidade de resistência do capitalismo. Ele parece exigir situações muito mais catastróficas que aquelas experimentadas recentemente para liberar todo o poder das ações de massa espontâneas, ultrapassando não apenas quem defende o capitalismo, mas o próprio sistema. Na medida em que as lutas recentes e futuras do proletariado escaparem ou escapem da influência e controle das autoridades capitalistas à qual a liderança do movimento trabalhista oficial também pertence - foram e serão movimentos que não podem ser integrados ao sistema capitalista e, portanto, constituem movimentos revolucionários reais.

JJL: Se novas greves gerais (como Maio de 68) ou outros movimentos revolucionários de massas crescerem, você pensa que eles podem evoluir para conselhos proletários, distante de partidos e sindicatos? Como? Em seu entender, o que pode ser feito para se livrar de partidos e sindicatos que impedem a auto-organização e a democracia direta?

PM: Em uma crise geral do capitalismo, sempre existe a possibilidade de que os movimentos sociais dela decorrentes possam ir além dos obstáculos colocados em seu caminho pelas formas tradicionais de ação econômica e política, e agirem de acordo com as novas necessidades, que incluem a necessidade de formas eficazes de organização. No entanto, assim como o capitalismo não vai renunciar por sua própria vontade, as organizações trabalhistas existentes tentarão manter ao máximo o controle desses movimentos sociais e orientá-los para objetivos favoráveis a si mesmas. No "melhor" dos casos - se falharem em ajudar a manter o status quo - elas dirigirão um possível levante revolucionário direcionado ao capitalismo de Estado, a fim de conservar as relações sociais de produção não somente para permitir sua existência futura, mas também para transformar suas organizações em instrumentos de um sistema capitalista modificado e as suas burocracias em uma nova classe dominante. Em resumo, eles tentariam transformar uma potencial revolução socialista em revolução capitalista de Estado, com resultados como os apresentados pelos chamados países socialistas. Eles podem ter sucesso em tais empreendimentos, no entanto, essa é a razão mais premente para defender e tentar estabelecer conselhos proletários em qualquer situação revolucionária, quanto para tentar concentrar neles toda a energia necessária para a autodeterminação proletária. O controle

Em Debat: Rev. Dig., ISSNe 1980-3532, Florianópolis, n. 10, p. 141-160, jul-dez, 2013. 
social por meio de conselhos proletários é uma possibilidade futura, dentre outras. A probabilidade de sua realização talvez seja menor que a probabilidade de uma transformação capitalista de Estado. Mas como esta não é uma solução para o problema inerente às relações sociais de exploração, uma possível revolução capitalista de Estado seria apenas adiar, sem eliminar, a necessidade de uma revolução tendo o socialismo como meta.

JJL: Você pensa que os conselhos são ainda hoje o modelo básico de uma sociedade comunista ou devem ser atualizados para atender às condições atuais do presente?

PM: O comunismo será um sistema de conselhos proletários ou não existirá. A "associação de produtores livres e iguais", que determina sua própria produção e distribuição, é pensável apenas como um sistema de autodeterminação nos locais de produção, e com a ausência de qualquer outra autoridade que não a vontade coletiva dos próprios produtores. Isso significa o fim do Estado, ou qualquer sistema estatal baseado na exploração. Deve ser uma produção planejada, sem a intervenção das relações de troca e as vicissitudes do sistema de mercado. A regulação do caráter social da produção deve descartar o fetiche do valor e as relações de preços, e deve ser realizada em termos de economia de tempo, com o tempo direto de trabalho como medida de cálculo, onde o cálculo ainda for necessário. O pressuposto de tal desenvolvimento é a ausência de um governo central com poder político próprio. As instituições centrais do sistema de conselhos são meras empresas dentre outras, sem um aparelho especial para fazer valer a sua vontade fora do consentimento dos outros conselhos ou de outras empresas. A estrutura do sistema deve ser de forma a combinar regulação central com autodeterminação dos produtores. Considerando que, sob as condições de subdesenvolvimento que os primeiros conselhos enfrentaram depois de uma revolução política bem-sucedida (a referência é a Rússia, em 1917), era praticamente impossível realizar uma sociedade comunista baseada em conselhos proletários. As condições vigentes nos países de capitalismo desenvolvido permitem realizar o socialismo muito melhor por meio do sistema de conselhos. É precisamente a forma mais avançada do capitalismo, com sua tecnologia avançada, alta produtividade e rede de comunicações, 
que oferece uma base material para o estabelecimento do comunismo com base em um sistema de conselhos proletários. A ideia dos conselhos não é uma coisa do passado, mas a proposta mais realista para o estabelecimento de uma sociedade socialista. Nada do que evoluiu durante as últimas décadas tirou-lhe a viabilidade; ao contrário, meramente fundamentou o caráter não-utópico dos conselhos proletários e a possibilidade do surgimento de uma verdadeira sociedade comunista.

\section{Lotta Continua entrevista Paul Mattick (outubro de 1977)}

Lotta Continua (LC): Parece que estamos entrando em um novo período de grave crise econômica e social. Quais as novas características deste período, comparado ao de 1930 ?

Paul Mattick (PM): As razões básicas para a crise atual são as mesmas que causaram todas as crises capitalistas anteriores. Mas toda crise possui também características específicas em relação ao seu início, às reações que elas despertam, e ao seu resultado. A estrutura mutável do capital responde por essas peculiaridades.

Em geral, uma crise acontece na sequência de um período de acumulação de capital bemsucedida, na qual os lucros produzidos e realizados são suficientes para manter uma determinada taxa de expansão. Este estado de prosperidade capitalista requer um aumento constante da produtividade do trabalho, grande o suficiente para compensar o declínio relativo da rentabilidade resultante da estrutura mutável de capital. A competitiva e, portanto, cega busca pelo lucro por parte dos capitalistas individuais não ajuda mas ignora a mudança na composição capital / trabalho do capital social. A crise estoura quando uma elevada desproporcionalidade entre uma taxa de lucro exigida para o capital social e sua necessária taxa de acumulação impede sua expansão futura. Esta discrepância subjacente - mas empiricamente indeterminável - vem à tona em termos de relações de mercado como falta de demanda efetiva, que é apenas outra expressão para a falta de acumulação de que a demanda efetiva depende.

Antes de 1930 períodos de depressão foram enfrentados com medidas deflacionárias, ou 
seja, deixar as "leis do mercado" seguirem seu curso na expectativa de que cedo ou tarde, a atividade econômica em declínio restauraria o equilíbrio perdido entre oferta e procura e, assim, faria reviver a rentabilidade do capital. A crise de 1930, no entanto, foi muito profunda e extensa para permitir se lidar com ela desta forma tradicional. Foi enfrentada com procedimentos inflacionários, ou seja, com intervenções governamentais nos mecanismos de mercado, ao ponto de se fazer uma guerra internacional, para reestruturar a economia mundial por meio de uma centralização forçada do capital em detrimento de capitais nacionais mais fracos, e pela absoluta destruição de capitais nas formas monetária e física. Financiados via déficits governamentais, isto é, por métodos inflacionários, os resultados ainda foram deflacionários, mas em escala muito maior do que havia sido realizado antes pela confiança passiva nas "leis do mercado". O longo período de depressão e a segunda guerra mundial, com a enorme destruição de capital a eles associados, criaram condições para um período extraordinariamente longo de expansão de capital nas principais nações ocidentais.

Assim, tanto deflação quanto inflação levaram ao mesmo resultado, a um novo crescimento do capital, e foram subsequente e alternadamente utilizadas na tentativa de garantir a estabilidade econômica e social recém-conquistada. Indubitavelmente, é possível animar uma economia estagnada por meio de financiamento de déficit, isto é, por meio do crédito. Mas não é possível manter a taxa de lucro sobre o capital dessa maneira, e assim, perpetuar as condições de prosperidade. Então, foi apenas questão de tempo até que o mecanismo da crise de produção de capital se reafirmasse. Obviamente que a mera disponibilidade de crédito para expandir a produção não é solução para a crise, mas uma política transitória e improvisada que apenas gera efeitos "positivos" temporários. Se não for acompanhada por uma verdadeira expansão do capital, baseada em lucros maiores, deve entrar em auto colapso. O "remédio keynesiano" levou apenas a uma nova situação de crise com o crescimento do desemprego e da inflação - ambos igualmente prejudiciais ao sistema capitalista.

A crise atual ainda não atingiu esse grau de devastação que, em 1930, levou da depressão à guerra. Embora incapazes de superar a atual crise, as medidas antidepressão aliviam em certa medida a miséria social causada pelo declínio da atividade econômica. Mas em uma economia capitalista estagnada, estas medidas se tornam parte de sua maior deterioração. 
Elas dificultam recuperar um ponto de partida para um novo crescimento. Além disso, o nível de "integração" internacional da economia capitalista, por meio de políticas liberais de comércio e arranjos monetários, é constantemente minado pelo aprofundamento da depressão. Tendências protecionistas perturbam o mercado mundial ainda mais. Como a depressão não pode ser superada, exceto às custas da população trabalhadora, a burguesia deve tentar todos os meios disponíveis, tanto econômicos quanto políticos, para reduzir o padrão de vida do proletariado. O aumento do desemprego, embora ajude, não basta para cortar salários o suficiente para aumentar a rentabilidade do capital. Os rendimentos de todas as camadas não capitalistas da sociedade devem ser reduzidos, as chamadas medidas de bem-estar diminuídas, na tentativa de chegar a essa rentabilidade do capital que permite a sua expansão. Apesar de uma rápida taxa de inflação possuir esse efeito, ela também encontra suas limitações na crescente anarquia da produção capitalista e na sociedade em geral. Como política permanente ela ameaça a existência do próprio sistema.

LC: Relacionado a isto, como você observa o papel da esquerda, em especial do Partido Comunista. Qual o significado do eurocomunismo?

PM: Deve-se distinguir na sociedade "esquerda objetiva", isto é, o proletariado como tal, de esquerda organizada, que não é de natureza estritamente proletária. Dentro da esquerda organizada, ao menos na Itália, o Partido Comunista ocupa a posição dominante. Especificamente neste momento, provavelmente ele determine as "políticas de esquerda", a despeito da oposição de outras organizações tanto à sua esquerda ou à sua direita. Mas o Partido Comunista não é uma organização comunista no sentido tradicional. Há muito que se transformou em uma formação social-democrata, um partido reformista, que se sente em casa dentro do sistema capitalista e, portanto, se oferece como instrumento de seu apoio. Na prática, o PC existe para satisfazer as aspirações burguesas de seus dirigentes e as necessidades de sua burocracia, mediando trabalho e capital, a fim de garantir o status quo social. O fato de grande parte da classe proletária segui-lo indica despreparo ou falta de vontade para derrubar o sistema capitalista dos proletários e, em vez disso, seu desejo de encontrar acomodação dentro do sistema. A 
ilusão de que isso é possível apoia as políticas oportunistas do Partido Comunista. Pelo fato de uma depressão prolongada ameaçar destruir o sistema capitalista, é essencial para o Partido Comunista - e para outras organizações reformistas - ajudar a burguesia superar as condições de crise. Devem, portanto, tentar impedir ações da classe proletária que possam atrasar ou impedir a recuperação capitalista. Suas políticas reformistas e oportunistas assumem um caráter abertamente contrarrevolucionário logo que o sistema se encontra ameaçado por atividades do proletariado que não podem ser atendidas nos marcos do sistema capitalista em crise.

O "eurocomunismo" ostentado pelo Partido Comunista não tem sentido, porque o comunismo não é uma categoria geográfica, mas social. Este termo vazio significa uma tentativa dos partidos comunistas europeus de diferenciar suas atitudes atuais de políticas passadas. Trata-se de uma declaração de que o objeto capitalista de Estado anterior, embora há muito esquecido, foi abandonado em favor de uma economia mista do capitalismo atual. "Eurocomunismo" é um pedido de reconhecimento oficial e de plena integração no sistema capitalista, que implica, naturalmente, uma integração nos vários Estados nacionais que compõem o território europeu. Significa uma busca por maiores "responsabilidades" no interior do sistema capitalista e de seus governos, uma promessa de não perturbar o limitado grau de cooperação alcançado pelas nações capitalistas no contexto europeu, e de se abster de qualquer atividade que possa perturbar o aparente consenso entre Oriente e Ocidente. Isso não implica romper radicalmente com a parte capitalista de Estado do mundo, mas apenas o reconhecimento, de que também esta parte não está interessada em expandir o sistema capitalista de estado por meios revolucionários, mas sim em uma integração completa com o mercado capitalista mundial, apesar das diferenças socioeconômicas que restam entre os sistemas de capitalismo privado e de Estado.

LC: Quais possibilidades existem para a ação revolucionária, ações que pretendem preparar uma futura revolução? Que possibilidades você visualiza para o proletariado empregado e desempregado, estudantes, grupos de esquerda?

PM: Para a derrubada do sistema, as ações revolucionárias são dirigidas contra ele como 
um todo. Isto pressupõe uma ruptura generalizada da sociedade, que escapa ao controle político. Até agora, tais ações revolucionárias ocorreram apenas em conexão com catástrofes sociais, como as que derivaram de guerras perdidas e de desorganizações econômicas a elas associadas. Isto não significa que tais situações sejam um pré-requisito absoluto para a revolução, mas indica o grau de desintegração social que antecede levantes revolucionários. Revolução deve envolver a maioria da população ativa. A necessidade, e não a ideologia, coloca as massas em movimento revolucionário. As atividades que resultam de tal movimento produzem sua própria ideologia revolucionária, a saber: uma compreensão do que tem que ser feito para sair vitorioso da luta contra os defensores do sistema. No momento as possibilidades de ações revolucionárias são extremamente sombrias porque as chances de sucesso são praticamente nulas. Devido às experiências anteriores, as classes dominantes esperam por atividades revolucionárias e se armaram para tanto. O seu poderio militar ainda não está ameaçado por divisões internas; politicamente ainda contam com o apoio das grandes organizações de trabalhadores e da maioria da população; elas ainda não esgotaram os mecanismos de manipulação da economia, e apesar de uma concorrência internacional cada vez maior para os lucros em retração da economia do trabalho, elas estão unidas em todo o mundo contra levantes proletários onde quer que ocorram. Nesta frente comum em defesa de suas próprias relações de exploração de classe, também se encontram os chamados regimes socialistas.

Enquanto uma revolução socialista - neste estágio de desenvolvimento - parece mais que duvidosa, todas as atividades da classe proletária em defesa de seus próprios interesses possuem um caráter potencialmente revolucionário porque o capitalismo se encontra em um estado de decadência que pode durar por longo tempo. Ninguém é capaz de prever as dimensões da depressão por ausência de dados relevantes. Mas todos enfrentam a crise real e tem de reagir a ela. A burguesia, à sua maneira, o proletariado de maneira oposta. Em períodos de relativa estabilidade econômica a própria luta do proletariado acelera a acumulação de capital, forçando a burguesia a adotar meios mais eficazes para aumentar a produtividade do trabalho e manter uma necessária taxa de lucro. Salários e lucros podem subir juntos sem perturbar a expansão do capital. A depressão, no entanto, faz com que este simultâneo (embora desigual) aumento de lucros e salários termine. A 
rentabilidade do capital deve ser restaurada antes que o processo de acumulação possa ser retomado. A luta entre trabalho e capital agora envolve a própria existência do sistema, vinculada à sua expansão contínua. Objetivamente, a luta econômica comum assume implicações revolucionárias e, portanto, formas políticas, porque uma classe apenas pode ter sucesso em detrimento de outra. O proletariado não precisa conceber sua luta como caminho para a revolução, pois no contexto de persistente declínio capitalista suas lutas assumem conotações revolucionárias para além de toda consciência.

É claro que os proletários podem estar preparados para aceitar, com limites, uma diminuição da sua parte do produto social, mesmo que apenas para evitar as mazelas de prolongados confrontos com a burguesia e seu Estado. Mas isso pode ser insuficiente para trazer um novo crescimento econômico e com isso não bastar para deter o aumento do desemprego. A divisão entre empregados e desempregados, enquanto uma necessidade capitalista, transforma-se em dilema capitalista com um desemprego em constante crescimento sob condições de estagnação econômica e declínio. Se alguém quiser sugerir ao proletariado como reagir ao aprofundamento da crise, tudo que poderia ser dito é para organizar empregados e desempregados em organizações sob seu controle direto, e para lutar por necessidades imediatas, independentemente da situação da economia e da solidariedade de classe do movimento trabalhista oficial. Em outras palavras, que se lute a luta de classes como a burguesia luta. A vantagem da burguesia, seu aparato estatal, deve ser correspondida com um poder maior, que, primeiramente, somente pode ser pela perturbação contínua do processo de produção - base de todo poder capitalista - e por atividades implacáveis dos desempregados para constranger os meios de existência da burguesia. No que se refere aos estudantes radicais e grupos revolucionários, a fim de serem de fato eficazes, devem se inserir em movimentos proletários e de desempregados. Não para realizar qualquer programa especial próprio, mas para articular o significado da luta de classes próxima com a direção a tomar devido às leis iminentes de produção de capital.

LC: Que papel você concebe para a violência na atividade radical, em particular para luta armada?

Em Debat: Rev. Dig., ISSNe 1980-3532, Florianópolis, n. 10, p. 141-160, jul-dez, 2013. 
PM: Esta pergunta não pode ser respondida atribuindo um papel positivo ou negativo à violência. A violência é inerente ao sistema, portanto uma necessidade tanto para o trabalho quanto para o capital. A burguesia somente pode existir em virtude do seu controle sobre os meios de produção, de modo que deve defender esse controle por meios extraeconômicos, por meio de seu monopólio sobre os meios de repressão. A recusa do trabalho, por sua vez, faz da posse dos meios de produção algo sem sentido, pois apenas o processo de trabalho fornece o lucro capitalista. Uma luta "puramente econômica" entre trabalho e capital está, portanto, fora de questão. A burguesia sempre suprimirá esta luta com violência onde quer que ameace a sua existência, ameaçando seriamente a rentabilidade do capital. Ela não permite ao proletariado escolher entre métodos nãoviolentos e violentos de luta de classe. É a burguesia, de posse do aparelho de Estado, que determina qual deles será em qualquer ocasião especifica. Violência somente pode ser respondida pela violência, mesmo que as armas empregadas sejam desiguais ao extremo. Nenhuma questão de princípio entra aqui, apenas a realidade da estrutura social classista. No entanto, a questão aqui colocada é se os elementos radicais nas lutas anticapitalistas devem ou não tomar a iniciativa de usar da violência, em vez de deixarem a decisão para a burguesia e seus mercenários. Evidentemente podem haver situações em que encontrem a burguesia despreparada nas quais um confronto violento com suas forças armadas poderia favorecer aos revolucionários. Mas toda a história dos movimentos radicais mostra claramente que tais ocorrências acidentais são de nenhum proveito. Em termos militares, a burguesia sempre terá vantagem. A menos que o movimento revolucionário assuma proporções tais que afete o próprio aparelho de Estado, por meio da divisão ou dissolução de suas forças armadas. Somente articulado a grandes movimentos de massa, que rompem totalmente o tecido social, que se torna possível arrancar os meios de repressão e com isso os meios de produção das classes dominantes.

A inutilidade de confrontos militares desiguais não tem sido capaz de impedi-los. Além disso, podem surgir situações onde tais confrontos disparem o gatilho para coisas maiores e levem a movimentos de massas, como geralmente são as condições prévias para a violência revolucionária. Por esta razão é tão perigoso insistir na não-violência e fazer da violência privilégio exclusivo da classe dominante. Mas aqui falamos de situações muito críticas, não como as que existem atualmente nos países capitalistas, e também sobre 
forças armadas grandes e suficientemente capazes de travar sua luta por um período de tempo considerável. Na ausência de tais situações muito críticas, tais ações não são mais do que suicídio coletivo, algo não indesejável para a burguesia. Elas podem ser apreciadas em termos morais ou mesmo estéticos, mas não servem para o curso da revolução proletária, exceto para entrar no folclore revolucionário.

Para pessoas revolucionárias é psicologicamente muito difícil, se não impossível, levantar suas vozes contra a inútil aplicação da "justiça revolucionária" por grupos terroristas e indivíduos. Mesmo Marx, que desprezava todas as formas de ação niilistas, não pode evitar de se sentir eufórico com as proezas terroristas da organização russa "Vontade do Povo". Na verdade, o contra terror de grupos revolucionários não pode ser evitado pelo mero reconhecimento de sua inutilidade. Seus perpetradores não são movidos pela convicção de que suas ações levarão diretamente para a mudança social, mas por sua incapacidade de aceitar o inquestionável, o terror perpétuo da burguesia sem resposta. E uma vez envolvidas no terror ilegal, as forças terroristas legalizadas lhes forçam a prosseguir suas atividades até o amargo fim. Este tipo de pessoas é em si um produto da sociedade classista e uma resposta à sua crescente brutalidade. De um ponto de vista proletário, não há sentido na formação de um consenso com a burguesia para condenar suas atividades. É suficiente reconhecer sua inutilidade e procurar maneiras mais eficazes para superar o onipresente terror capitalista pelas ações de classe do proletariado.

Em Debat: Rev. Dig., ISSNe 1980-3532, Florianópolis, n. 10, p. 141-160, jul-dez, 2013. 